\title{
Appling Recyclable Waste Tire for Crude Oil Absorption
}

\section{Zahra Zamiraei*, Mohammadreza Golriz and Mehran Parsa}

Environmental Research Institute, Academic Center for Education, Culture \& Research (ACECR), 4144635699, Rasht, Iran

*Corresponding author: Zahra Zamiraei, Environmental Research Institute, Academic Center for Education, Culture \&

Research (ACECR), 4144635699, Rasht, Iran. E-mail: zamiraei@acecr.ac.ir

Received: March 07, 2018; Accepted: March 12, 2018; Published: March 18, 2018

\section{Abstract}

Crude oil spillage is a major environmental pollution in the world. Tire rubber is flexible and has hydrophobic (oil-philic) characteristics, making it a good candidate as oil absorbent. This study is used ASTM F726-99 method to evaluate oil absorbing capability of tire powder. In this paper, the possibility of applying waste tire powder as an absorbent for the recovery of spilled oil was investigated. The results indicate that averagely $1.75 \mathrm{~g}$ of crude oil can be absorbed to each gram of 120 mesh tire powder. Due to its elastic property, waste tire powder is re-usable for several times only down to $50 \%$ decreasing its oil absorption efficiency. The best absorption was obtained at pH 7. The results of this study showed that sorption efficiency increased as the over time, and decreased as the environmental temperature increases. The results indicated the low-cost tire powder can be used in any water oil-spill conditions.

Keywords: Waste tire powder; Oil absorbent; Crude oil; Oil spillage; Recycling

\section{Introduction}

In recent years, frequent oil-spill accidents have caused severe ecological problems, including nearly irreversible damage to ecological systems. There has been an increasing concern about the environmental risk of industrial activities associated with oil extraction [1]; accidental and intentional oil discharges have been reported frequently during the transportation, production, and oil refining, and these have a severe negative impact on organisms and the wider environment and ecology [2-4].

Numerous approaches for the removal of oil from oily water emulsions have been reported in the literature, including filtration (ultra and micro), reverse osmosis, gravity separation, activated sludge treatment, various flotation methods (dissolved air, column flotation, gasaphrons, electro and induced air), membrane bioreactors, biological treatment, chemical coagulation, electro-coagulation and coalescences $[5,6]$.

Absorbent materials are attractive for some applications because of the possibility of collection and complete removal of the oil from the oil spill site [7,8]. The addition of absorbents to oil spill areas facilitates a change from liquid to semi-solid phase and once this change is achieved, the removal of the oil by removal of the absorbent structure then becomes much easier. Furthermore, these materials can, in some cases, be recycled. Some properties of good absorbent materials include

Citation: Zamiraei Z, Golriz M, Parsa M. Appling Recyclable Waste Tire for Crude Oil Absorption, Iran. J Curr Chem Pharm Sci. 2018;8(1):110.

(C) 2018 Trade Science Inc. 
hydrophobicity and oleophilicity, high uptake capacity, high rate of uptake, retention over time, oil recovery from absorbents, and the reusability and biodegradability of the absorbents [9].

According to Gunasekara et al., tires are primarily composed of rubber (40-45\%) vulcanized with sulfur (1.5-2.5\%), steel, and carbon black (27-33\%) [10]. The carbon black, used to strengthen the rubber, is similar to activated carbon, a good sorbent to remove dissolved organic substances from wastewater [11].

It was further investigated the use of ground discarded tires to remove naphthalene and toluene from water [10]. Moreover, tire rubber is a flexible and hydrophobic (oil-philic), making it a good candidate as an oil sorbent. In this research, the possibility of utilizing waste tire powder as oil sorbent for the recovery of spilled oil has been explored.

\section{Materials and Methods}

\section{Materials}

Crude oil was obtained from Tehran Oil Refining Company, Iran. The 120 mesh tire powder was obtained froma local scrap tire recycling facility in Tehran, Iran. A fine mesh which allowed the passing of oil was used to package in polypropylene during the sorption experiments.

\section{Method}

The American Society of Testing and Materials F726-99 method was referenced for oil sorption capability tests.

1-L beakers were used for the absorption test [12]. Each of the set of five beakers contained $100 \mathrm{~cm}^{3}$ of $\mathrm{crude}$ oil. In all cases the ratio of crude oil to water was 1:5 by volume. One gram of recycled rubber of particle sizes $0.1 \mathrm{~mm}$ was used.

All tests were performed at $24^{\circ} \mathrm{C}$ room temperature. First, the waste tire powder in polypropylene package (package $25 \times 25$ $\left.\times 10 \mathrm{~mm}^{3}\right)$ was immersed in the crude oil/water mixture (100:500 ml) for about $15 \mathrm{~min}$. Then the package was removed from the solution, held for 2 min s to allow the surface residual liquid to drip away, and then weighed.

The sorption capacity of the waste tire powder was expressed in grams of the pollutant (crude oil) absorbed by per gram of the waste tire powder $\left(\mathrm{g} \mathrm{g}^{-1}\right)$ :

$$
Q_{t}=\frac{m_{t}-m_{o}}{m_{o}}
$$

where $\mathrm{Q}_{\mathrm{t}}\left(\mathrm{g} \mathrm{g}^{-1}\right)$ is the sorption capacity of the waste tire powder package at a certain time $\mathrm{t}(\mathrm{s})$, $\mathrm{m}_{\mathrm{t}}(\mathrm{g})$ is the weight of the waste tire powder package after absorption, and $\mathrm{m}_{0}(\mathrm{~g})$ is the initial weight of the waste tire powder package.

The reusability of the tire powder packaging was characterized by simple squeezing operations. After a saturated sorption, the tire powder was squeezed for $10 \mathrm{~s}$ under press process. Then the package was weighed and reused for subsequent sorption tests.

\section{Result and Discussion}

The selection of cost-effective hydrophobic absorbents depends on many factors. The precursor should be easily available, inexpensive, and non-hazardous. Necessary physical characteristics include high abrasion resistance and high thermal stability, while small pores lead to a high exposed surface area and, hence, to a high surface capacity for absorption [6]. The tire powder includes most of them.

\section{Effect of time on absorption}


The oil absorption of tire powder was investigated at the different time. FIG. 1 shows the results of the sorption tests for the $60 \mathrm{~min}$ and, as expected, sorption increases for the over time, from 5 to $60 \mathrm{~min}$.

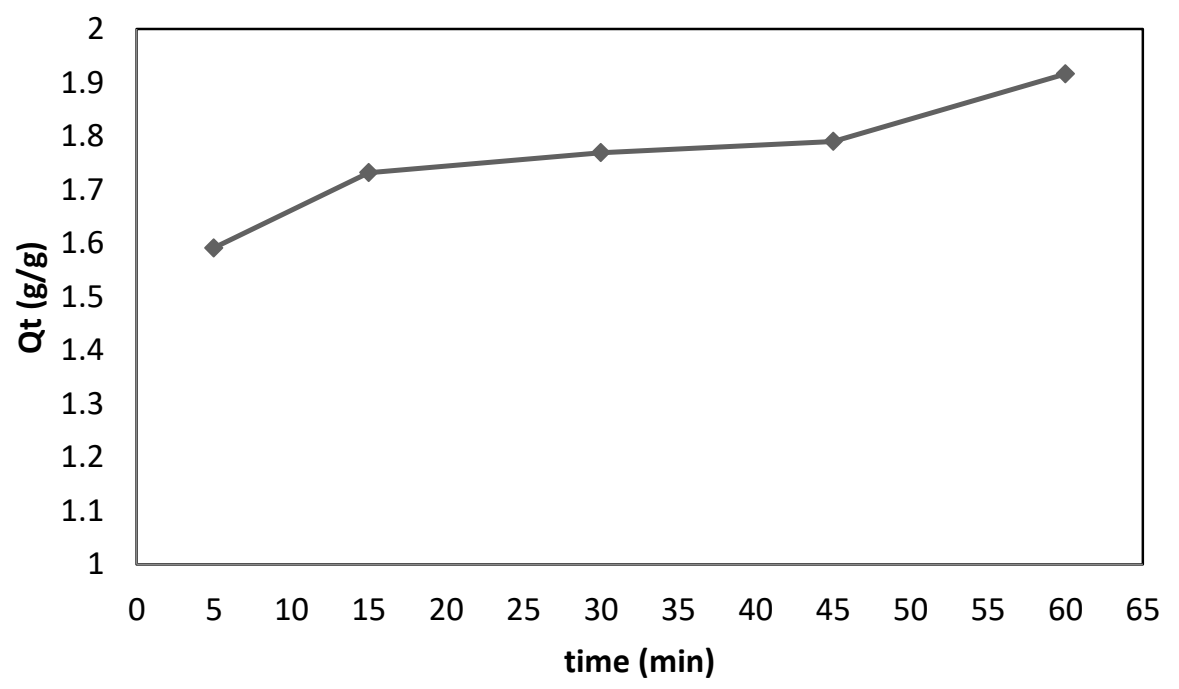

Figure 1: Crude oil absorption of tire powder for $60 \mathrm{~min}$

\section{Effect of the pH on absorption}

The $\mathrm{pH}$ factor is very important in the absorption. The crude oil absorption of tire powder was tested at different $\mathrm{pH}$ levels ranging from 5 to 8 . The maximum absorbance was obtained at $\mathrm{pH} 7$ (FIG. 2).

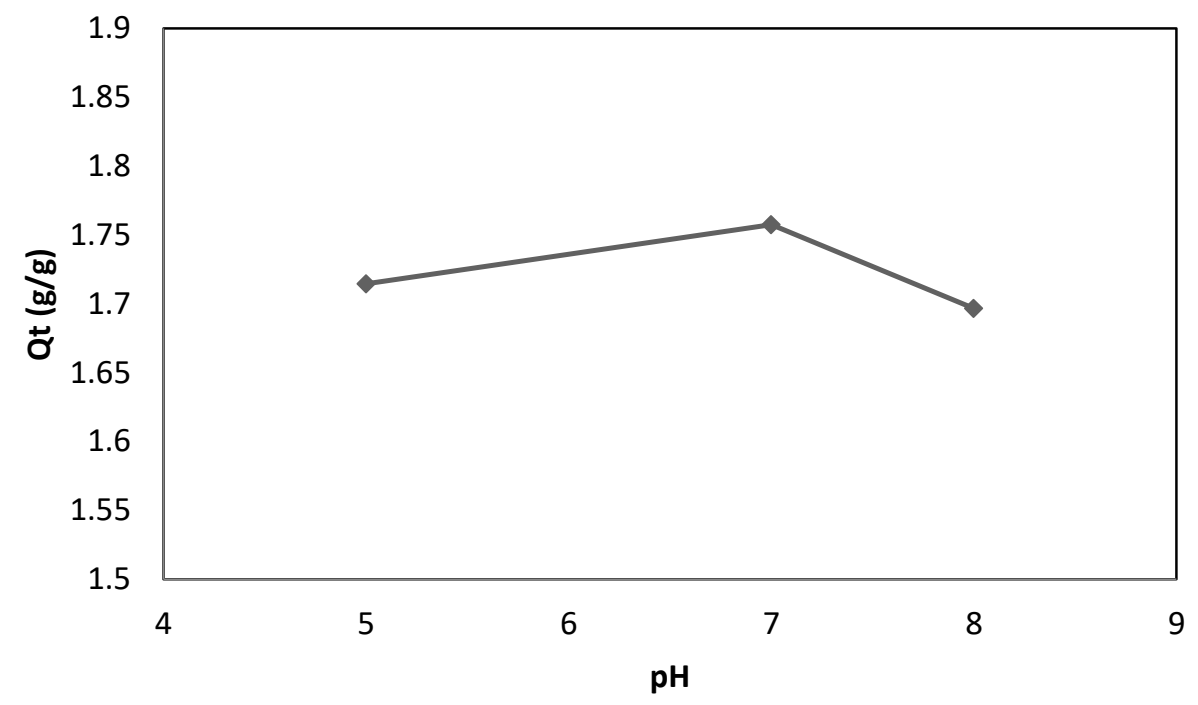

Figure 2: Crude oil absorption of tire powder at different $\mathbf{p H}$

\section{Effect of the Temperature on absorption}

FIG. 3 shows the oil sorption capacity of the tire powder decreases with increases in temperature. Higher temperatures lead to a low viscosity in oil, making it difficult for the oil to adhere to the sorption material. When the temperature decreases, oil 
viscosity increases and making much more sorption of oil possible, suggesting that the tire powder would recover more oil in cold regions than in warm regions.

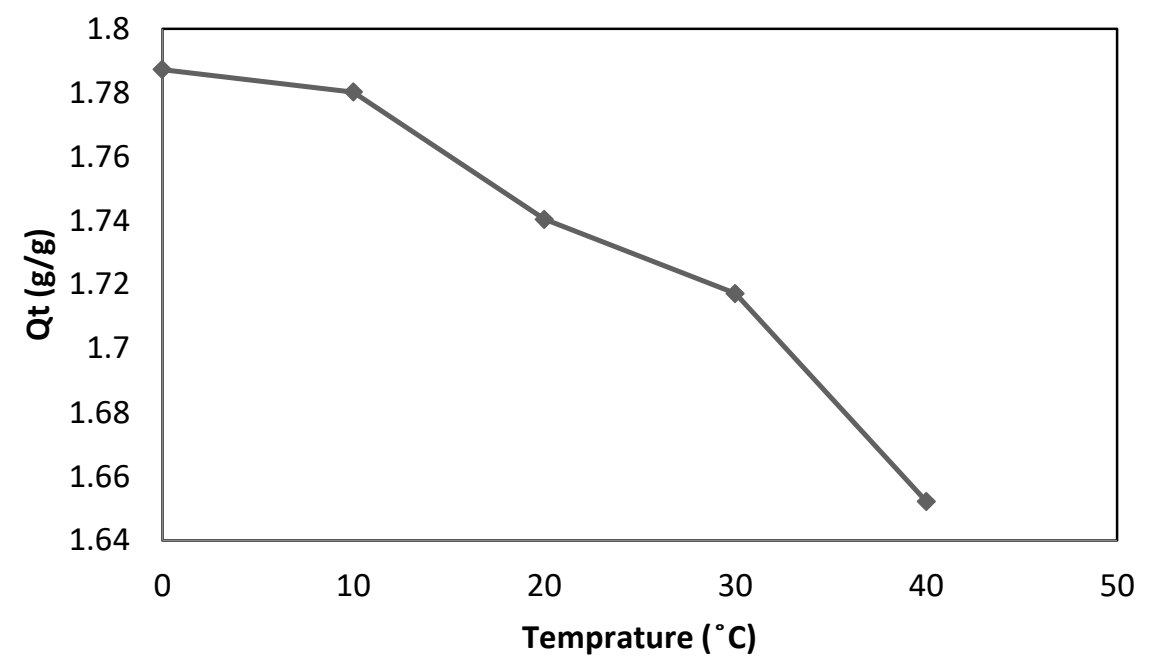

Figure 3: Crude oil absorption of tire powder at different temperature

\section{Repeated use of tire powder}

FIG. 4 shows the oil absorption for $1 \mathrm{~g}$ 120-mesh tire powder after each use for the several reuses. Because tire powder has good elasticity, it was able to maintain it oil sorption capacity at $50 \%$ of earlier after 5 times uses.

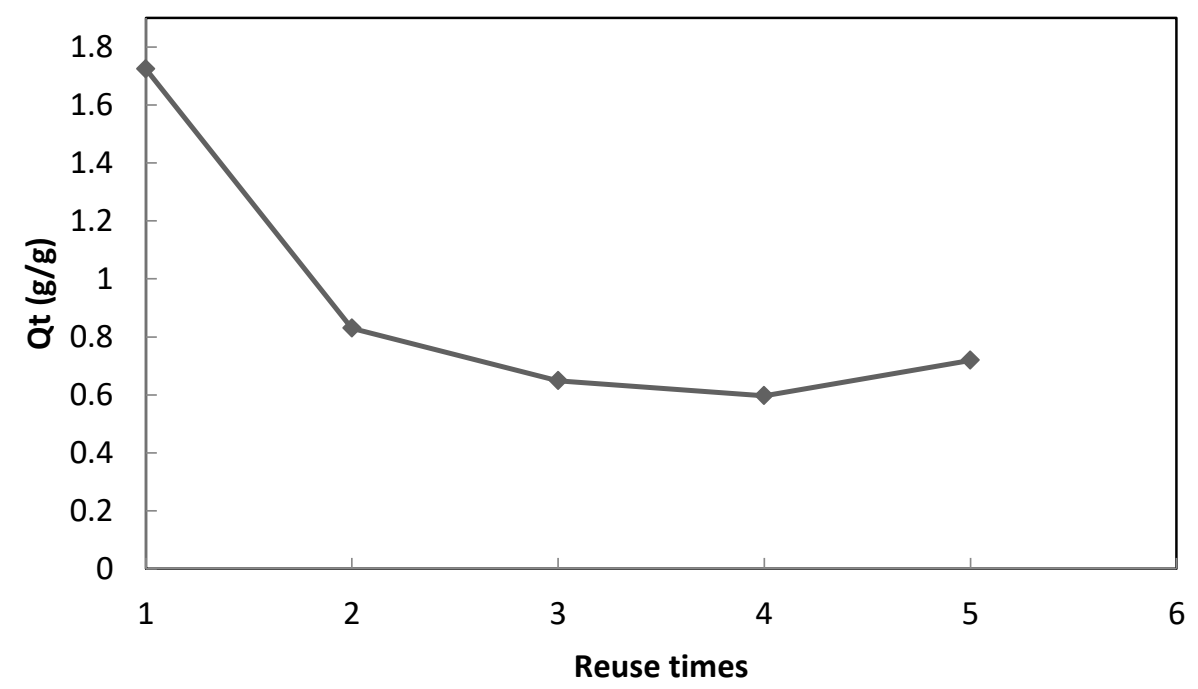

Figure 4: Re-usability of waste tire powder for crude oil absorption.

\section{Conclusions}

Waste tire powder is flexible and has oil-philic characteristics, making it a suitable candidate as oil absorbent for the recovery of oil spills. The use of tire powder as sorbents of crude oil was investigated in various conditions, in different $\mathrm{pH}$, 
temperature, time and reusability of tire powder. The best sorption capacity of the tire powder was obtained at pH 7. The oil sorption capacity of the tire powder decreases with increases in temperature. As expected, absorption increased over time from 5 to $60 \mathrm{~min}$. Because tire powder has good elasticity, it was able to maintain it oil sorption capacity at $50 \%$ of earlier after 5 times uses. The tire powder showed a rapid oil sorption due to high degree of hydrophobicity and low water uptake. The results indicated the low-cost tire powder can be used in any water oil-spill conditions and the best method for applying the waste tire powder.

\section{REFERENCE}

1. Gui X, X Zeng Z, Lin X, et al. Magnetic and Highly Recyclable Macroporous Carbon Nanotubes for Spilled Oil Sorption and Separation. ACS Appl Mater Interfaces 2013;5:5845-5850.

2. 2. Wanga D, Mc Laughlin E, Feffer RP. Adsorption of Oils from Pure Liquid and Oil-Water Emulsion on Hydrophobic Silica Aerogels. Separation and Purification Technology 2012;99:28-35.

3. 3. Alonso-Alvarez C, Pérez C, Velando A. Effects of Acute Exposure to Heavy Fuel Oil From the Prestige Spill on A Seabird. Aquatic Toxicology 2007;84:103-110.

4. 4. Ahmad AL, Bhatia S, Ibrahim N, et al. Adsorption of Residual Oil from Palm Oil Mill Effluent using Rubber Powder. Brazil Journal of Chemical Engineering 2005;22:371-379.

5. 5. Santander M, Rodrigues RT, Rubio J. Modified Jet Flotation in Oil (Petroleum) Emulsion/Water Separations. Colloid Surface 2011;375: 237-244.

6. 6. Sabir S. Approach of Cost-Effective Adsorbents for Oil Removal from Oily Water. Critical Reviews in Environmental Science and Technology 2015;45:1916-1945.

7. 7. Sharafimasooleh M, Bazgir S, Tamizifar M, et al. Adsorption of Hydrocarbons on Modified Nanoclays. Proceeding IOP Conference Series: Materials Science and Engineering. IOP Publishing 2011;18:182012.

8. 8. Tansel B, Pascual B. Removal of Emulsified Fuel Oils from Brackish and Pond Water by Dissolved Air Flotation with and Without Polyelectrolyte Use: Pilot-Scale Investigation for Estuarine and Near Shore Applications. Chemosphere 2011;85:1182-1186.

9. 9. Adebajo MO, Frost RL, Kloprogge JT, et al. Porous Materials for Oil Spill Cleanup: A Review of Synthesis and Absorbing Properties. Journal of Porous Materials 2003;10:159-170.

10. 10. Gunasekara AS, Donovan JA, Xing B. Ground Discarded Tires Remove Naphthalene, Toluene, and Mercury from Water. Chemosphere 2000;41:1155-1160.

11. 11. Snoeyink VL, Walter J, Weber WJ. The Surface Chemistry of Active Carbon; A Discussion of Structure and Surface Functional Groups. Environmental Science \& Technology 1967;1:228-234.

12. 12. American Society of Testing and Materials, ASTMF:726-99. 